\title{
Holmium:YAG Laser for the Treatment of Genital and urethral Warts: Multicentre Prospective Evaluation of Safety and Efficacy
}

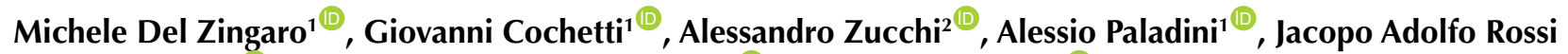 \\ De Vermandois ${ }^{\circledR}{ }^{\oplus}$, Sara Ciarletti ${ }^{1}$, Graziano Felici ${ }^{*{ }^{*}}$, Giuseppe Maiolino ${ }^{1 \oplus}$, Roberto Renzetti ${ }^{3}$, Gianluca \\ Gaudio $^{1}{ }^{\circledR}$, Ettore Mearini ${ }^{\circledR}$
}

'Department of Surgical and Biomedical Sciences, Division of Urology Clinic, University of Perugia, Perugia, Italy ${ }^{2}$ Department of Urology, University of Pisa, Pisa, Italy

${ }^{3}$ Department of Surgeries, Urology, Presidio Ospedaliero Pescara, Pescara, Italy

\section{*Correspondence to Graziano Felici, Urology Resident, Department of Surgical and Biomedical Sciences, Division of Urology Clinic, University of Perugia, Piazzale Giorgio Menghini, 1, 06129 Perugia (PG), Italy. \\ Tel: +39 075 5783898/4416; Email: graziano.felici@gmail. com}

Received: September 15, 2020 Accepted: January 6, 2021 Published online July 10, 2021

\begin{abstract}
Introduction: Genital condylomatosis is a highly contagious disease caused by the human papilloma virus (HPV). The aim of this prospective multicentre study was to evaluate the safety and efficacy of the Holmium:YAG (yttrium-aluminium-garnet) laser in the treatment of genital and intra-urethral warts; the secondary aim was to assess the patients' postoperative satisfaction and cosmetic results. Methods: From December 2016 to March 2019, patients with genital warts were prospectively enrolled in three hospitals. The inclusion criteria were male gender, age over 18 years-old and treatment-naïve. External and urethral genitalia warts were treated by the Holmium YAG laser. The follow-up analysis consisted of physical examination, flexible urethro-cystoscopy in case of meatal lesions, and administration of Dermatology Quality of Life Index (DLQI) and Patient Global Impression of Improvement (PGI-I) questionnaires at 1, 3, 6 and 12 months after surgery and subsequently yearly.

Results: Sixty patients were enrolled. The single treatment was effective in 57/60 patients (95\%). At a mean follow-up of 26 months, recurrences occurred in 8 patients $(13.3 \%)$. No peri- or postoperative complication occurred. An improvement in pre-operative condition was highlighted with PGI-I and DLQI questionnaires.

Conclusion: Our prospective multicentre study showed that holmium laser surgery seems to be a safe and effective treatment for external genital and urethral warts. Good dermatological outcomes aid to further improve patient satisfaction.

Keywords: Genital warts; Holmium laser; Patient satisfaction; Recurrence.
\end{abstract}

\section{Introduction}

Genital condylomatosis is a highly contagious disease caused by the human papilloma virus (HPV). There are over $100 \mathrm{HPV}$ serotypes, with at least 30 serotypes potentially causing genital infection. ${ }^{1,2}$ HPV 6 and 11 are responsible for approximately $90 \%$ of benign genital warts, while a close association has been shown between infection by some other serotypes, especially HPV 16, HPV 18, HPV 31, HPV 33 HPV 35, HPV 45, HPV 51, HPV 52, HPV 56, HPV 58, HPV 59 and HPV 73, and cancerous lesions of genitalia, anus and oropharynx.,.$^{2,3}$ There are about 3-4 million new cases of genital warts every year, with a higher incidence in people aged between 25 and 29 years. ${ }^{4}$ This common disease causes psychological and physical troubles, as well as a high social healthcare cost, estimated at 6 billion dollars annually in the United States. ${ }^{5}$ Men or women are infected through skin/mucous direct contact during oral, genital or anal intercourse and more often from women to men, especially in immunocompromised patients. ${ }^{6-8}$ Through microscopic abrasions due to sexual intercourse, HPV is able to penetrate into the mucosa and infect the epithelial basal cells. The breakage of the infected cell induces the immune response by the activation of the mediated T-Helper immune system with the release of interleukins and interferon. Once the infection occurs, the HPV can remain undetected for months before showing the warty lesions. ${ }^{9-11}$ Cellular changes range from slight cytological alterations, such as koilocytosis, to precancerous and malignant ones. Among people infected by genital HPV, only a small percentage ( $1 \%-5 \%)$ develops genital warts, while the rest do not present any skin lesion and any specific symptoms. ${ }^{12}$ Typically, genital lesions appear as multiple warts, sized from a few millimetres up to a few 
centimetres, with uncertain colour, but more frequently pink-brownish. In males, the most involved sites are glans, coronary sulcus, frenulum preputii and penis shaft, while external meatal and intra-urethral warts account for about $20 \%$ of all the urogenital condylomatosis. ${ }^{13}$ These lesions should be differentiated from the epidermoid cyst, Fordyce spots, condyloma latum, lichen planus, molluscum contagiosum, pearly penile papules, seborrheic keratosis, and squamous cell carcinoma of the penis. ${ }^{14}$

Diagnosis is mainly based on the physical examination of lesions. The application of acetic acid is no longer recommended because the result does not change clinical management. ${ }^{15,16}$ A Biopsy is not routinely performed, but it could be significantly helpful if diagnosis is doubtful or if lesions are not responsive to standard therapy or worsen during therapy. Many treatments are reported in the literature, including topical creams, dichloroacetic or trichloroacetic acid, cryotherapy, surgical removal by a laser or electrocauterization. ${ }^{17}$ Although no treatment has been stated to be better than others, laser therapy is accounted among the most successful. ${ }^{18,19}$ To our knowledge, only few studies have evaluated the efficacy of the holmium laser as the treatment of genital and urethral warts.

We reported our experience in the treatment of male external genitalia and urethral warts using the Holmium:YAG (yttrium-aluminium-garnet) laser. The primary aim of this prospective multicentre study was to evaluate the safety and efficacy of Holmium:YAG laser treatment. The secondary aim was to assess the patients' postoperative satisfaction.

\section{Material and Methods}

From December 2016 to March 2019, the patients with genital and/or urethral warts were prospectively enrolled in three hospitals.

The inclusion criteria were male patients with warts, aged over 18 years, who had previously received no medical or surgical treatments for genital warts. The exclusion criteria were female gender, age under 18 years, presence of asymptomatic bacteriuria or urinary tract infections (UTIs), presence of sexually transmitted diseases, genital candidiasis, immunocompromised patients, including those undergoing transplant, and previous medical or surgical treatment for genital warts. Diagnostic management included physical examination for warts of the external genitalia, and in patients with meatal and peri-meatal warts, urethroscopy up to the urinary sphincter was carried out to evaluate the urethral involvement. Therefore, external genitalia warts were treated by the Holmium:YAG laser after the application of local anesthesia using lidocaine/prilocaine cream (Emla $\left.{ }^{\oplus}\right)$ (Figure 1). The fiber calibre was $230 \mu \mathrm{m}$ and the laser treatment was carried out at the maximum energy of 0.8 -
$1.0 \mathrm{~J}$, at a pulse frequency between 10 and $12 \mathrm{~Hz}$, with 6 to $10 \mathrm{~W}$ average power. After the routine decontamination of the area of the lesions, the wart was treated by the holmium laser with a $1-\mathrm{mm}$ margin of healthy tissue, inserting the fiber into the surface of the condyloma. After removing warts, residual necrotic tissue was cleaned by gauze. In patients with meatal and perimeatal warts, flexible urethroscopy was carried out after the application of lidocaine jelly $2.5 \%$ as local anaesthesia for 5 minutes. When intra-urethral warts were found, they were removed by the laser up to the submucosa; in order to prevent damaging the urethral wall, laser energy was delivered to the condyloma, keeping the fiber parallel to the urethral wall, and the circular use of the laser beam was avoided to prevent the formation of strictures. For the 3 months following the operation, condom use was advised during sexual intercourse. The follow-up treatment consisted of physical examination in all patients, whilst flexible urethroscopy was also performed in those treated for meatal, peri-meatal and urethral warts at 1, 3, 6 and 12 months after surgery and then yearly. The following clinical endpoints were examined: (1) the efficacy of the treatment which was assessed on the basis of the cure rate, defined as the complete removal of warts, and the recurrence rate; (2) the safety of the treatment which

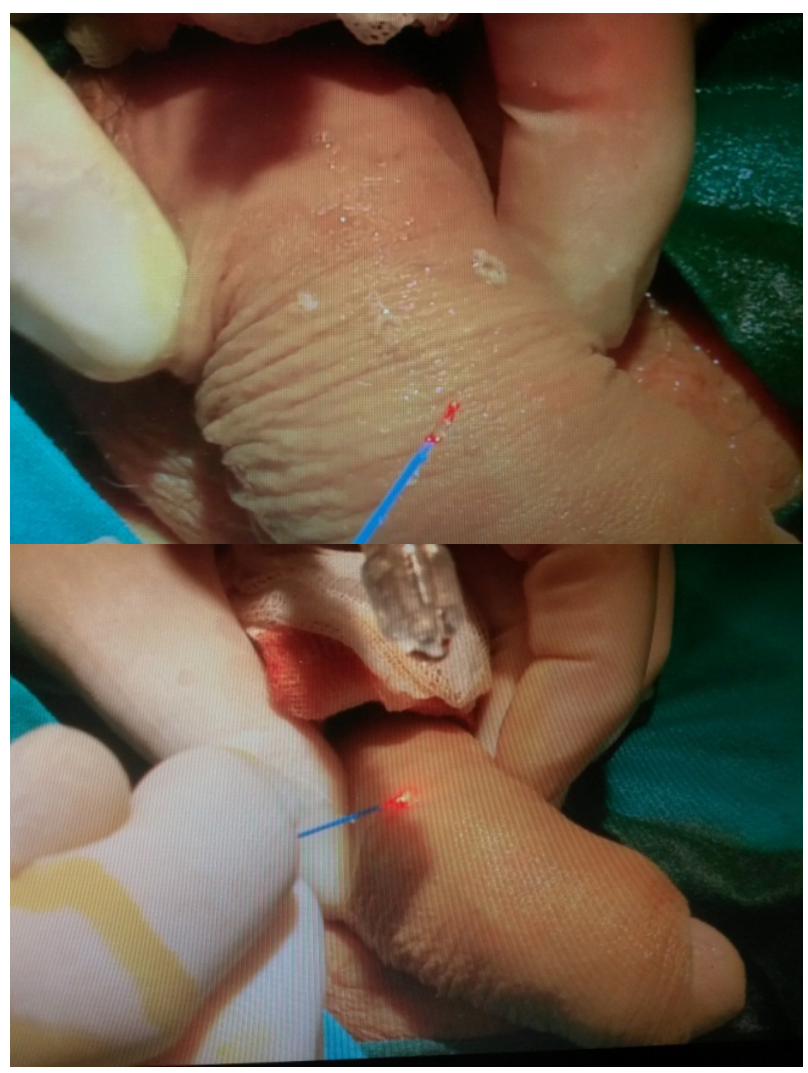

Figure 1. Holmium:YAG Laser Treatment of Condyloma Acuminata. Images represent our minimally invasive surgical technique $(a, b)$. 
was evaluated according to peri- and post-operative complications; (3) the impact of urogenital warts on the quality of life and the degree of patient satisfaction.

Clavien-Dindo Classification was used to evaluate peri- and post-operative complications. ${ }^{20}$ Dermatology Quality of Life Index (DLQI) and Patient Global Impression of Improvement (PGI-I) questionnaires were administered before surgery and at 1, 3, 6, 12 months after surgery to evaluate the impact of genital warts on patient's quality of life and to assess the postoperative satisfaction rate respectively. ${ }^{21,22}$ The study was approved by the institutional review board, and informed consent was obtained from each patient. We used an internal institutional laser safety protocol which was based on the recommendations of the European Association of Urology Guidelines. ${ }^{23}$

\section{Statistical Analysis}

We conducted a descriptive statistical analysis to summarize the variables collected: parametric variables were given as the mean (min-max) while non-parametric variables as their absolute and relative frequencies ( $\mathrm{n}$, $\%)$. DLQI score results were classified according to the following ranges: $0-1$ (no effect at all on patient's life), 2-5 (small effect on patient's life), 6-10 (moderate effect on patient's life), 11-20 (very large effect on patient's life) and 21-30 (extremely large effect on patient's life). Statistical analysis was performed using SPSS version 11.5 (SPSS, Chicago, Illinois).

\section{Results}

In the present study, a total of 60 patients were enrolled with a mean age of 33.9 ranging from 24 to 71 years. The median number of lesions was 8 , ranging from 1 to 24 with a mean size of $9 \mathrm{~mm}$ (range $1-15 \mathrm{~mm}$ ). Table 1 reports demographic and clinical data of the study population. Genital warts involved glans, coronary sulcus, frenulum, penile shaft in $44(73.4 \%)$ patients, external urethral meatus and penile urethra in $14(23.3 \%)$ patients; 2 (3.3\%) patients showed lesions on the anus and perianal regions in addition to glans (Figure 2). The mean operative time was 24 minutes (range: 18-45 minutes). The cure rate was $95 \%(57 / 60)$ by a single treatment, while 3 patients needed a second session. At a mean followup of 26 months (range 12-39), the recurrence rate was $13.3 \%$ (8/60): in 2 patients warts recurred on glans, while in 6 patients they were localized on the anterior urethra. Therefore, in these patients, further endoscopic laser treatment was performed. No peri- or post-operative complications occurred according to Clavien-Dindo classification. No urethral stricture or UTIs were found in patients undergoing endoscopic treatment. After a median time of 16 days (range: 15-20), no patient showed dystrophic-permanent ulcerative lesions related to laser therapy. In all patients, sexual activity recovery occurred within 30 days after the treatment. PGI-I questionnaire at 12 months highlighted $36(60 \%)$ patients who evaluated their post-operative condition as "very much better" and $24(40 \%)$ as "much better". No patient declared "no change" status. At 12 months, 36 patients (60\%) reported a DLQI score between 1 and 2, 22 (36.7\%) between 2 and 3 , and $2(3.3 \%)$ between 6 and 10. However, in the latter group, no additional therapy was necessary because the transient symptoms resolved spontaneously. Concerning the results of 8 recurrence cases, 6 (75\%) of them showed no treatment-related adverse effects, while 2 (25\%) referred to independent transient ones at DLQI.

\section{Discussion}

Genital warts are the most common sexually transmitted infection and approximately $20 \%$ of them are found in the male urethra. ${ }^{11,13} \mathrm{Up}$ to now, the best therapeutic option has not been established, and the decision-making of the most appropriate strategy should be based on the number, size, site and morphology of the lesions, as well as the performance status of the patient and the cost and adverse effects of the treatment. Traditional treatments including topical therapies, cryotherapy, surgical excision and electrosurgery are often complicated by a high recurrence rate and may have bothersome side effects such as pain, scarring and oedema. Unfortunately, the latter are even higher when urethral condylomata are involved. ${ }^{17,19,24}$

Laser therapy vaporizes affected tissues through focused, infrared light energy, and the benefits of this treatment include a high rate of cure, painless manoeuvre, quick healing, lower infection levels and a low rate of

Table 1. Demographic and Clinical Data of Our Sample

\begin{tabular}{lc}
\hline Variables & No. (\%) \\
\hline Age classes $(y)$ & $29(48.3 \%)$ \\
$24-29$ & $17(28.3 \%)$ \\
$30-39$ & $7(11.7 \%)$ \\
$40-49$ & $4(6.7 \%)$ \\
$50-59$ & $2(3.3 \%)$ \\
$60-69$ & $1(1.7 \%)$ \\
$70-71$ & \\
Ethnicity & $60(100 \%)$ \\
Caucasian & \\
Smoking status & $39(65 \%)$ \\
Current smoker & $21(35 \%)$ \\
Never or former smoker & \\
Comorbidity & $22(36,7 \%)$ \\
Hypercholesterolemia & $5(8,33 \%)$ \\
COPD & $1,67 \%)$ \\
DM type 2 & \\
\hline Allergic asthma & \\
\hline
\end{tabular}




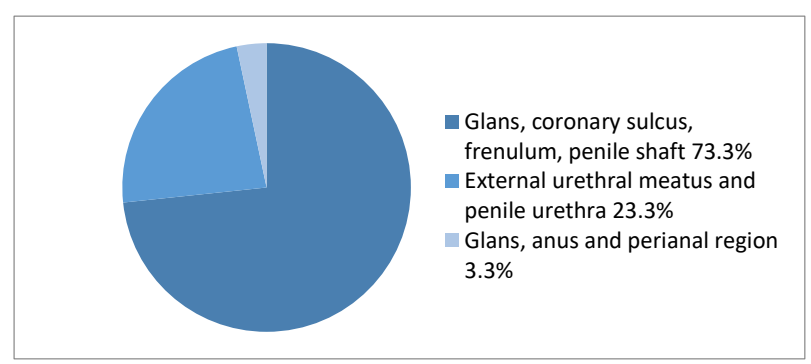

Figure 2. Localization of Genital Warts in Our Cohort.

recurrence and complications. To our knowledge, the overall cure rate of laser therapy ranges from $43 \%$ to 100\% (Table 2). The recurrence rate has been different depending on the type of laser energy: $19-33 \%$ for the $\mathrm{CO}_{2}$ laser, 5-23\% for the pulsed dye laser, 35\% for Argon, 0-60\% for neodymium-doped yttrium aluminum garnet (Nd:YAG), 33\% for thulium and 16\% for holmium. ${ }^{24,26}$ The Nd:YAG and Thulium laser can be used for both external and urethral warts, showing similar results in terms of cure, complications and recurrence rate. Although the Thulium laser seems to be the ideal energy source with a minor risk of scarring because of minimal penetration in the tissue, the Holmium:YAG laser represents an innovative and effective treatment of genital and urethral warts. ${ }^{24}$ Holmium:YAG energy can be easily absorbed by human tissue and it has been demonstrated to be safe in the treatment of genital, perianal and intraurethral warts. ${ }^{26}$
The Holmium laser has a wavelength of $2140 \mathrm{~nm}$ and a tissue penetration depth of $400 \mu \mathrm{m}$, and the developed energy is absorbed by water. Thanks to this peculiarity, the Holmium laser, compared to other laser sources, has a less penetration depth and constant absorption in tissue. Consequently, the photo-thermal effect allows radical treatment of skin or mucosa lesion respecting the surrounding tissue with a lower rate of scars.

The adequate extension of treatment seems to be the key factor affecting the recurrence rate, more than the depth of the laser penetration. This is because at the time of treatment the cells surrounding the warts could already have a latent HPV infection. Moreover, HPV infection could be disseminated to other cells near the primary wart during the treatment.

Our prospective multicentre study highlighted a clearance rate of $95 \%$ with a recurrence rate of $13.3 \%$ at a mean follow-up of 26 months. Focusing on urethral warts, overall, 14 endoscopic laser ablations were carried out for naïve cases with a success rate of $100 \%$ and a recurrence rate of $42.8 \%(6 / 14)$. We did not include female patients to avoid a confounding factor. These findings showed the single session of the treatment with the holmium laser was very effective in each type of genital wart, including widespread condyloma or urethral one. These findings are in line with previous studies reporting a clearance rate of $60 \%-100 \%$ and a recurrence rate of $3 \%$ $77 \%{ }^{18,27,36,37}$ In a recent retrospective study comparing

Table 2. Laser Therapy Data on Genital Warts Treatment in Literature

\begin{tabular}{|c|c|c|c|c|c|c|c|c|}
\hline Author & Year & $\begin{array}{c}\text { No. of } \\
\text { Patients }\end{array}$ & $\begin{array}{l}\text { No. of } \\
\text { lesions }\end{array}$ & $\begin{array}{c}\text { Size of } \\
\text { Lesions }(\mathrm{mm})\end{array}$ & Cure Rate & $\begin{array}{c}\% \text { Wart } \\
\text { Recurrence }\end{array}$ & $\%$ Complications & $\begin{array}{l}\text { Follow-up } \\
\text { (mon) }\end{array}$ \\
\hline \multicolumn{9}{|c|}{ Holmium:YAG laser } \\
\hline Ghiasy et $\mathrm{al}^{25}$ & 2019 & 101 & 9.8 (median) & NA & $92.2 \%$ & $14.3 \%$ & NA & 6 (mean) \\
\hline Ge et $\mathrm{al}^{26}$ & 2014 & 25 & NA & 3 (mean) & $88 \%$ & $16 \%$ & $24 \%$ & 6 \\
\hline Yang et $\mathrm{al}^{27}$ & 2008 & 1500 & NA & NA & $99.2 \%$ & NA & NA & 7.5 (mean) \\
\hline \multicolumn{9}{|c|}{ Carbon dioxide laser } \\
\hline Padilla-Ailhaud ${ }^{28}$ & 2006 & 81 & $\mathrm{NA}$ & NA & $83 \%$ & $14.8 \%$ (6 months) & NA & 18.8 (mean) \\
\hline Duus et $\mathrm{al}^{29}$ & 1985 & 21 & $\mathrm{NA}$ & NA & $43 \%$ & NA & NA & 6 \\
\hline Reid $^{30}$ & 1985 & 32 & NA & up to 10 & $97 \%$ & $52 \%$ & $10.4 \%$ & NA \\
\hline \multicolumn{9}{|l|}{ Pulsed dye laser } \\
\hline Veitch et $\mathrm{al}^{31}$ & 2017 & NA & NA & NA & $52-100 \%$ & $0-5 \%$ & NA & NA \\
\hline Badawi et $\mathrm{al}^{32}$ & 2006 & 174 & 3.82 (mean) & 26.9 (mean) & $96 \%$ & $5 \%$ & NA & 4 \\
\hline Komericki et $\mathrm{al}^{33}$ & 2006 & 22 & NA & $<10$ & $100 \%$ & $23 \%$ & NA & 11 (mean) \\
\hline \multicolumn{9}{|l|}{ Thulium laser } \\
\hline Blokker et al ${ }^{24}$ & 2013 & 39 & $\mathrm{NA}$ & NA & NA & $33.3 \%$ & $5.1 \%$ & 13.5 \\
\hline \multicolumn{9}{|l|}{ Nd:YAG laser } \\
\hline Blokker et $\mathrm{al}^{24}$ & 2013 & 76 & NA & NA & NA & $34.2 \%$ & $5.3 \%$ & 17.8 \\
\hline Zaak et $\mathrm{al}^{34}$ & 2003 & 168 & NA & NA & NA & $35.7 \%$ & $10.1 \%$ & 12 \\
\hline \multicolumn{9}{|l|}{ Argon laser } \\
\hline Viazis et $\mathrm{al}^{35}$ & 2007 & 25 & NA & NA & NA & $34.7 \%$ & $0 \%$ & 10.5 (mean) \\
\hline
\end{tabular}

Abbreviations: YAG, Yttrium Aluminum Garnet; NA, not available; Nd, Neodymium 
the Holmium laser, cryotherapy, conventional surgery and podophyllin, Ghiasy et al found that the Holmium laser was the best treatment of genital and meatal warts, with the highest clearance rate (92.2\%) through a single session and the lowest recurrence rate (14.3\%), compared to other treatments. ${ }^{25}$ However, the follow-up period of this study was only 6 months, and the patients treated by the holmium laser were 39 . Yang et $\mathrm{al}^{27}$ reported the results from a large cohort study in which 1500 patients with genital and urethral warts were treated using the Holmium laser. Overall, the authors found that $28 \%$ of patients were cured after a single session treatment, whilst this percentage dropped to $15.9 \%$ for urethral warts. However, this observational study included patients with very large warts and also female patients with cervix uteri; on average, every patient was treated 2.68 times and the mean times of treatment were significantly higher in urethral $(\mathrm{n}=69)$, anal $(\mathrm{n}=285)$ and cervix uteri $(\mathrm{n}=$ 132) lesions as well as in large ones. This, in addition to a larger study population, could be the reason for the low clearance rate by a single session treatment in comparison with our findings.

In our study, no patient showed significant or lasting adverse effects such as burning, pain, erythema and oedema of the treated area, abnormal wound healing or dystrophic-ulcerative permanent lesions. No stenosis or abnormal scarring or UTI occurred when endoscopic treatment was performed. A disadvantage of the Holmium laser is that it is a pulsed laser instead of a continuous wave. During the 300 milliseconds pulse of the laser, water is instantly turned into an exploding vapor bubble that expands and ruptures the surrounding tissue up to 3-4 mm. Although major tissue damage is expected due to this rupture, our findings as well as those of Yang et al showed no complications due to scarring. ${ }^{27}$ Conversely, if warts are located in the urethra, the $\mathrm{CO}_{2}$ laser and cryotherapy could often cause stenosis and oedema respectively. ${ }^{38-41}$

Two/three weeks after the treatment, the patients could return to normal sexual activity, with a considerable degree of satisfaction due to fast functional recovery. According to the PGI-I questionnaire, all patients evaluated their post-operative condition as "very much better" or "much better" and only 2/60 (3.3\%) referred to mild and transient burning according to DLQI. ${ }^{42}$ These findings are in accordance with the previous studies of the safety profile of laser therapy. ${ }^{5,43-45}$

Indeed, laser treatment allows reducing bleeding and post-operative pain by cauterizing blood vessels and by sealing nerve endings respectively. ${ }^{46}$

The treatment was also well tolerated by the patients with urethral warts, despite the fact that only local anesthesia was performed. Overall, our study showed an excellent result as regards the degree of patient satisfaction. The strengths of this study were the prospective and multicentre nature and long-term follow-up. However, the main limitations were the small sample size and the lack of information about HPV genotyping.

\section{Conclusion}

Our prospective and multicentre study showed that Holmium laser surgery seems to be a safe and effective treatment of genital and urethral warts. Due to the decreased depth of action and constant absorption in the treated area, this laser guarantees accurate preservation of surrounding healthy tissues, with a quick functional recovery. Good dermatological outcomes aid to further improve patient satisfaction. Further randomized prospective trials should be conducted to compare the main different treatments and to identify the best therapeutic strategy.

\section{Ethical Considerations}

The study was approved by the internal institutional review board, and was conducted in accordance with ethical principles of the Helsinki declaration. The informed consent was obtained from each patient.

\section{Conflict of Interests}

The authors declare that they have no competing interests.

\section{Funding Sources}

This study was not supported by any external sources of funding.

\section{Reference}

1. Suligoi B, Salfa M, Mariani L, Corsini D, Timelli L, Fattorini G, et al. A New Surveillance Gynecological Network to Assess the Incidence and Prevalence of Genital Warts in the Italian Female Population: Lessons Learned. Minerva Ginecol. 2013;65:577-85.

2. Suligoi B, Vittori G, Salfa MC, Timelli L, Corsini D, Fattorini $\mathrm{G}$, et al. Prevalence and incidence of external genital warts in a sample of Italian general female population. BMC Infect Dis. 2017;17:126. doi:10.1186/s12879-017-2202-6

3. Gissmann L, Hausen H zur. Partial characterization of viral DNA from human genital warts (condylomata acuminata). Int J Cancer. 1980;25:605-9. doi:10.1002/ijc.2910250509.

4. Insinga RP, Dasbach EJ, Myers ER. The Health and Economic Burden of Genital Warts in a Set of Private Health Plans in the United States. Clin Infect Dis. 2003;36:1397403. doi:10.1086/375074.

5. de Lima MM, de Lima MM, Granja F. Treatment of genital lesions with diode laser vaporization. BMC Urol. 2015;15:39. doi:10.1186/s12894-015-0033-6

6. Park IU, Introcaso C, Dunne EF. Human Papillomavirus and Genital Warts: A Review of the Evidence for the 2015 Centers for Disease Control and Prevention Sexually Transmitted Diseases Treatment Guidelines. Clin Infect Dis. 2015;61:S849-55. doi:10.1093/cid/civ813.

7. Gagliotti C, Morsillo F, Moro ML, Masiero L, Procaccio F, Vespasiano F, et al. Infections in liver and lung transplant recipients: a national prospective cohort. Eur J Clin Microbiol Infect Dis. 2018;37:399-407. doi:10.1007/s10096- 
018-3183-0.

8. Errico G, Gagliotti C, Monaco M, Masiero L, Gaibani $\mathrm{P}$, Ambretti S, et al. Colonization and infection due to carbapenemase-producing Enterobacteriaceae in liver and lung transplant recipients and donor-derived transmission: a prospective cohort study conducted in Italy. Clin Microbiol Infect. 2019;25:203-9. doi:10.1016/j.cmi.2018.05.003.

9. Stubenrauch F, Laimins LA. Human papillomavirus life cycle: active and latent phases. Semin Cancer Biol. 1999;9:379-86. doi:10.1006/scbi.1999.0141.

10. Stanley MA. Epithelial cell responses to infection with human papillomavirus. Clin Microbiol Rev. 2012;25(2):215222. doi:10.1128/CMR.05028-11

11. Yanofsky VR, Patel RV, Goldenberg G. Genital warts: a comprehensive review. J Clin Aesthet Dermatol. 2012;5(6):25-36.

12. O’Mahony C. Genital Warts: Current and Future Management Options. Am J Clin Dermatol. 2005;6:239-43. doi:10.2165/00128071-200506040-00004.

13. Oriel JD. Natural history of genital warts. Br J Vener Dis. 1970; 47(1):1-13

14. Karnes JB, Usatine RP. Management of External Genital Warts. Am Fam Physician. 2014;90:312-8.

15. Workowski KA. Centers for Disease Control and Prevention Sexually Transmitted Diseases Treatment Guidelines. Clin Infect Dis. 2015;61: S759-62. doi:10.1093/cid/civ771.

16. Workowski KA, Bolan GA. Centers for Disease Control and Prevention. Sexually Transmitted Diseases Treatment Guidelines, 2015. MMWR Recomm Rep. 2015; 64(RR03):1-137.

17. Wiley DJ, Douglas J, Beutner K, Cox T, Fife K, Moscicki A, et al. External Genital Warts: Diagnosis, Treatment, and Prevention. Clin Infect Dis. 2002; 15;35(Suppl 2): S210-24. doi:10.1086/342109.

18. Stone KM, Becker TM, Hadgu A, Kraus SJ. Treatment of external genital warts: a randomised clinical trial comparing podophyllin, cryotherapy, and electrodesiccation. Genitourin Med. Treatment of external genital warts: a randomised clinical trial comparing podophyllin, cryotherapy, and electrodesiccation. Genitourin Med. 1990;66:16-9. doi:10.1136/sti.66.1.16.

19. Leung AK, Barankin B, Leong KF, Hon KL. Penile warts: an update on their evaluation and management. Drugs Context. 2018; 7: 212563.. doi:10.7573/dic.212563

20. Dindo D, Demartines N, Clavien P-A. Classification of Surgical Complications. Ann Surg. 2004; 240(2):205-13. doi:10.1097/01.sla.0000133083.54934.ae.

21. Basra MKA, Fenech R, Gatt RM, Salek MS, Finlay AY. The Dermatology Life Quality Index 1994-2007: a comprehensive review of validation data and clinical results. Br J Dermatol. 2008; 159(5): 997-1035.doi: 10.1111/ j.1365-2133.2008.08832. x.

22. Karmakar D, Mostafa A, Abdel-Fattah M. A new validated score for detecting patient-reported success on postoperative ICIQ-SF: a novel two-stage analysis from two large RCT cohorts. Int Urogynecol J. 2017; 28:95-100. doi:10.1007/s00192-016-3070-0.

23. Handa KK, Bhalla AP, Arora A. Fire during the use of Nd-Yag laser. Int J Pediatr Otorhinolaryngol. 2001 Sep 28;60(3):239-42. doi: 10.1016/s0165-5876(01)00525-0.[18
24. Blokker RS, Lock TMTW, de Boorder T. Comparing thulium laser and Nd:YAG laser in the treatment of genital and urethral condylomata acuminata in male patients. Lasers Surg Med. 2013; 45(9):582-8. doi:10.1002/lsm.22181

25. Ghiasy S, Fallah-Karkan M, Razzaghi MR, Ranjbar A, Rahavian A, Javanmard B. Is Holmium Laser an Appropriate Modality to Treat Genital Warts? J Lasers Med Sci. 2019; 10(1): 70-74. doi:10.15171/jlms.2019.11.

26. Ge C, Jiang J, Jiang Q, Liu C, Hu Z, Liang $\mathrm{P}$, et al. Holmium:YAG Laser Ablation Combined Intraurethral Fluorouracil Perfusion as Treatment Option for Intraurethral Condyloma Acuminata in Men. Minerva Urol Nefrol. 2014; 66(1):77-81

27. Yang C, Liu S, Liu J, Wang Z, Luo D, Zhang G, et al. Holmium Laser Treatment of Genital Warts: an Observational Study of 1500 Cases. Acta Derm Venereol. 2008;88(2):136-8. doi:10.2340/00015555-0354.

28. Padilla-Ailhaud A. Carbon Dioxide Laser Vaporization of Condyloma Acuminata. J Low Genit Tract Dis. 2006;10(4):238-41. doi:10.1097/01. lgt.0000225890.21539.79.

29. Duus BR, Philipsen T, Christensen JD, Lundvall F, Sondergaard J. Refractory condylomata acuminata: a controlled clinical trial of carbon dioxide laser versus conventional surgical treatment. Genitourin Med. 1985;61(1):59-61. doi:10.1136/sti.61.1.59.

30. Reid R. Superficial laser vulvectomy. Am J Obstet Gynecol. 1985;151(8):1047-52. doi:10.1016/0002-9378(85)90378-3.

31. Veitch D, Kravvas G, Al-Niaimi F. Pulsed Dye Laser Therapy in the Treatment of Warts. Dermatol Surg. 2017;43(4):485-93. doi:10.1097/DSS.0000000000001023.

32. Badawi A, Shokeir HA, Salem AM, Soliman M, Fawzy S, Samy N, et al. Treatment of genital warts in males by pulsed dye laser. J Cosmet Laser Ther. 2006;8(2):92-5. doi:10.1080/14764170600617490.

33. Komericki P, Akkilic M, Kopera D. Pulsed dye laser treatment of genital warts. Lasers Surg Med. 2006;38(4):2736. doi:10.1002/lsm.20293.

34. Zaak D, Hofstetter A, Frimberger D, Schneede P. Recurrence of condylomata acuminata of the urethra after conventional and fluorescence-controlled Nd:YAG laser treatment. Urology. 2003;61(5):1011-5. doi:10.1016/S00904295(02)02527-X

35. Viazis N, Vlachogiannakos J, Vasiliadis K, Theodoropoulos I, Saveriadis A, Karamanolis DG. Earlier Eradication of Intra-Anal Warts with Argon Plasma Coagulator Combined with Imiquimod Cream Compared with Argon Plasma Coagulator Alone: A Prospective, Randomized Trial. Dis Colon Rectum. 2007;50(12):2173-9. doi:10.1007/ s10350-007-9041-2.

36. Beutner KR, Wiley DJ, Douglas JM, Tyring SK, Fife K, Trofatter K, et al. Genital Warts and Their Treatment. Clin Infect Dis. 1999;28:S37-56. doi:10.1086/514722.

37. McMillan A, Scott GR. Outpatient treatment of perianal warts by scissor excision. Genitourin Med. 1987;63(2):1145. doi:10.1136/sti.63.2.114.

38. Gill H. Laser treatment of genital condylomata acuminata. West J Med. 1996; 164(4): 341.

39. Grundsell H, Larsson G, Bekassy Z. Treatment of condylomata acuminata with the carbon dioxide laser. $\mathrm{Br}$ 
J Obstet Gynaecol. 1984; 91: 193-196. doi: 10.1111/j.14710528.1984.tb05906.x.

40. Sood S, Hruza GJ. Treatment of verruca vulgaris and condyloma acuminatum with lasers. Dermatol Ther. 2000; 13(1):90-101. doi:10.1046/j.1529-8019.2000.00010.x

41. Perisic Z, Lazic JP, Terzic B, Perisic S, Rasic R. Condylomata gigantea in anal and perianal region: surgical and $\mathrm{CO} 2$ laser treatment. Arch Gynecol Obstet. 2003; 267(4):263-265. doi: 10.1007/s00404-002-0468-3.

42. Andrews M. Cryosurgery for Common Skin Conditions. Am Fam Physician. 2004;69(10):2365-72.

43. Carrozza PM, Merlani GM, Burg G, Hafner J. CO(2) Laser Surgery for Extensive, Cauliflower-Like Anogenital Condylomata acuminata: Retrospective Long-Term Study on 19 HIV-Positive and 45 HIV-Negative Men.
Dermatology. 2002;205(3):255-9. doi:10.1159/000065844.

44. Aynaud O, Buffet M, Roman P, Plantier F, Dupin N. Study of persistence and recurrence rates in 106 patients with condyloma and intraepithelial neoplasia after $\mathrm{CO} 2$ laser treatment. Eur J Dermatol. 2008;18(2):153-8. doi: 10.1684/ ejd.2008.0353.

45. Tuncel A, Görgü M, Ayhan M, Deren O, Erdogan B. Treatment of Anogenital Warts by Pulsed Dye Laser. Dermatol Surg. 2002;28(4):350-2. doi:10.1046/j.15244725.2002.01172.x.

46. Goharkhay K, Moritz A, Wilder-Smith P, Schoop U, Kluger W, Jakolitsch S, et al. Effects on oral soft tissue produced by a diode laser in vitro. Lasers Surg Med. 1999;25(5):4016. doi:10.1002/(sici)1096-9101(1999)25:5<401::aidlsm6>3.0.co;2-u. 